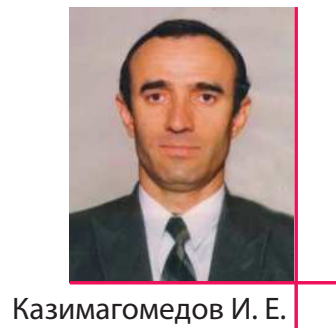

Казимагомедов И. Е.
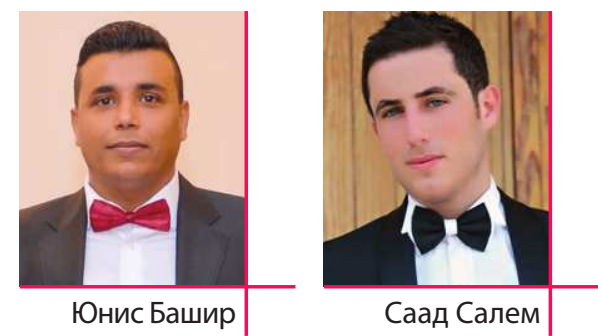

Казимагомедов И. Е., к.Т.Н.,

доцент кафедры строительных материалов и изделий,

Харьковский национальный университет

строительства и архитектуры (ХНУСА),

ул. Сумская, 40, г. Харьков, 61002

¿+38 (097) 992-46-03凶kazimagomedov.1957@mail.ru,

Юнис Башир, к.т.н.,

доцент кафедры строительной механики,

Харьковский национальный университет

строительства и архитектуры (ХНУСА),

ул. Сумская, 40, г. Харьков, 61002

×+38 (093) 661-04-94凶 docbasheer01@gmail.com,

Саад Салем, аспирант,

๘+38 (093) 528-06-35凶 sesonoor@yahoo.com

Харьковский национальный университет

строительства и архитектуры (ХНУСА),

ул. Сумская, 40, г. Харьков, 61002
Ibrahim Kazimagomedov, Ph.D.,

assistant professor of building materials and products Department

Kharkiv National University

of Civil engineerng and Architecture,

Str. Sumy, 40, Kharkov, 61002

๘ +38 (097) 992-46-03凶 kazimagomedov.1957@mail.ru,

Basheer N. Younis, Ph. D.,

assistant professor of structural mechanics Department

Kharkiv National University

of Civil engineerng and Architecture,

Str. Sumy, 40, Kharkov, 61002

๘+38 (093) 661-04-94凶 docbasheer01@gmail.com,

Saad Salem, postgraduate student,

s+38 (093) 528-06-35凶sesonoor@yahoo.com

Kharkiv National University

of Civil engineerng and Architecture,

Str. Sumy, 40, Kharkov, 61002

\title{
ОЦЕНКА ФАКТОРОВ ЭФФЕКТИВНОСТИ ЗАМЕНЫ \\ СЕТЕЙ ТРУБОПРОВОДОВ МИКРОАРМИРОВАННЫМИ ТРУБАМИ
}

\section{ОЦІНКА ФАКТОРІВ ЕФЕКТИВНОСТІ ЗАМІНИ МЕРЕЖ ТРУБОПРОВОДІВ МІКРОАРМОВАНИМИ ТРУБАМИ ASSESSMENT OF FACTORS OF EFFICIENCY OF REPLACEMENT OF PIPELINE NETWORKS BY MICRO-REINFORCED PIPES}

Аннотация. В статье приводится сравнительный анализ эффективности замены аварийных сетей водоснабжения Украинына разработанные автором бетонные микроармированные трубы. Приведена экспертная оценка влияния факторов на эффективность трубопроводов.

Ключевые слова: эффективность, железобетонные трубы, бетонные микроармированные трубы, критерии оптимальности, факторы эффективности. Анотація. У статті наводиться порівняльний аналіз ефективності заміни аварійних мереж водопостачання Украінини розробленими автором бетонними мікроармованими трубами. Наведена експертна оцінка впливу факторів на ефективність трубопроводів.

Ключові слова: ефективність, залізобетонні труби, бетонні мікроармована труби, критерії оптимальності, фактори ефективності.

Abstract. The article provides a comparative analysis of the effectiveness of replacing emergency water supply networks of Ukraine with concrete micro-reinforced pipes developed by the author. An expert assessment of the influence of factors on the efficiency of pipelines is given.

Keywords: efficiency, reinforced concrete pipes, concrete microreinforced pipes, optimality criteria, efficiency factors.

\section{Введение}

Традиционно бетонные и железобетонные трубопроводы применяются в водоводах хозяйственно-бытовой, ливневой, промышленной канализации, дренажных, ирригационно-мелиоративных и т.д [1]. Долговечность трубопроводов в значительной степени зависит от условий эксплуатации, степени агрессивности среды, и физико-механического состава транспортируемоего материала [2].

\section{Актуальность проблемы}

Ввиду наличия значительных недостатков у железобетонных труб, на долю которых приходится около 30\% трубопровода Украины, значительная часть магистральных сетей находится в аварийном состоянии. Так, согласно статистике жилищно-коммунального хозяйства [3], В декабре 2018 года Министерство регионального развития, строительства и жилищно-коммунального хозяйства Украины сообщило: «Общая протяжённость канализационных сетей [Украины] - 34 650,0 км, из которых в аварийном состоянии находится 13043,0 км, или
37,6\%». Кроме того, было отмечено, что количество насосного оборудования в системах водоотведения Украины составило 7106 единиц, из них требует замены 1854 или 26,1%.[3]

В марте 2011 года отмечалось: «В соответствии с ними [официальными данными], около 35 \% канализационных сетей [Украины] находятся в аварийном и ветхом состоянии. Наибольший удельный вес таких проблемных сетей - на Харьковщине $(50,7 \%)$, в АР Крым $(50,4 \%)$, в Донецкой и Луганской областях (соответственно 48,8 \% и 47,5 \%). По словам Юрия Хиврича, преимущественно очистительные сооружения эксплуатируется по 30-40 лет и только 10 \% из них введены в эксплуатацию меньше 15 лет назад. Старые сооружения исчерпали свой эксплуатационный ресурс, поэтому крайне нуждаются в срочной реконструкции и замене. Ряд регионов вообще нуждаются в безотлагательном развитии централизованной системы водоотвода. Так, населенные пункты Виннитчины обеспечены таким водоотводом на 2,3 \%, Сумщины - на 2,7\%, Черниговщины - на 2,8 \%, Хмельнитчины - на $3 \%$, Полтавщины - на 3,3\%, Кировоградщины - на 3,6\%. 
Да и в целом по Украине этот показатель выглядит довольно скромно - 5,7 \% от общей численности населенных пунктов.»[12]

Такая ситуация требует от специалистов всестороннего анализа проблемы и эффективной стратегии ее решения [3]. Ремонтно-восстановительные работы трубопроводных сетей водоснабжения являются затруднительными и малоэффективными ввиду высокой себестоимости реконструкции (рисунок 1) [4].

Учитывая актуальность проблемы реконструкции и замены трубопроводных систем, был проведен анализ возможности замены традиционных железобетонных труб на микроармированные бетонные трубы.

Характерной особенностью современной строительной технологии является применение химических добавок, наполнитетей, позволяющими регулировать свойства бетона в широком диапазоне. Как указывал Дворкин О.Л. [6], введение добавок позволяет удешевить процесс изготовления бетона, поскольку дополнительные затраты часто перекрываются уменьшением стоимости необходимых материальных ресурсов, снижением расхода цемента, увеличением межремонтных сроков и т.д. Учитывая значительную протяжённость трубопроводов в Украине, снижение стоимости строительства может быть достигнуто путём экономии сырья, используемого для производства труб. Мероприятия по совершенствованию структуры трубопроводов, прежде всего, должны быть направлены на повышение их качественных показателей, таких как надёжность, экономичность и долговечность [4].

Рассмотрим экономический эффект при производстве микроармированных бетонных труб. Затрагивая вопрос эффективности наиболее полное определение,

отображающее суть понятия звучит следующим образом: эффективность - это показатель соотношения возможных результатов целевого применения предлагаемого решения и затрат, обеспечивающих его достижение. Для того чтобы среди возможных вариантов решений найти наилучший и наиболее эффективный, необходимы критерии, характеризующие эффективность достижения поставленных целей. Этот критерий должен быть выражен в виде определённых показателей - критерия оптимальности, который бы однозначно характеризовал любой из возможных вариантов реализации решения. Наилучшим вариантом решения при этом следует считать тот, который даёт в зависимости от конкретной задачи и принятого критерия оптимальности минимальное или максимальное значение [9].

\section{Эффективность трубопроводов}

Рассматривая понятие эффективности относительно видов трубопроводов, автор сталкнулся с тем, что в литературе нет точных показателей, так называемых критериев оптимальности, которые бы давали объективную характеристику трубам. В различных источниках, описывающих трубопроводы, приводяться те или иные признаки и показатели; так одни производители считают основными факторами качества труб экономичность, соблюдение гигиенических и пожарных требований, устойчивость к различным воздействиям, другие же приводять в пример инные, не упомяная первых. Кроме этого производители трубопроводов часто игнорируют описания характеристик, на соответствующий товар, не упомяная недостатки, которые часто бывают существенными. Следует отметить, что при описании характеристик строительных изделий необходимо строго

Экспертная оценка влияния факторов на эффективность использования трубопроводов

\begin{tabular}{|c|c|c|c|c|}
\hline № & Наименование фактора & $\begin{array}{c}\text { Весомость } \\
\text { фактора, \% }\end{array}$ & $\begin{array}{c}\text { Экспертная } \\
\text { оценка }\end{array}$ & Потенциал \\
\hline 1 & прочность & 5 & 5 & \begin{tabular}{|l|l}
$\ln$ & 25 \\
\end{tabular} \\
\hline 2 & морозостойкость & 4,995 & 4 & \begin{tabular}{|l|l|l|} 
and & 19,98 \\
\end{tabular} \\
\hline 3 & экономичность & 4,999 & 5 & 24,995 \\
\hline 4 & экологичность & 4,965 & 4 & 19,86 \\
\hline 5 & трудовые затраты & 4,943 & 4 & 19,772 \\
\hline 6 & долговечность & 4,999 & 5 & 24,995 \\
\hline 7 & объёмная масса (вес) & 4,874 & 5 & 24,37 \\
\hline 8 & дополнительные расходы & 4,895 & 4 & 19,58 \\
\hline 9 & огнестойкость & 3,967 & 2 & 7,934 \\
\hline 10 & пропускная способность & 4,971 & 4 & 19,884 \\
\hline 11 & теплопроводность & 4,983 & 4 & 19,932 \\
\hline 12 & коррозийная стойкость & 4,947 & 5 & 24,735 \\
\hline 13 & звукопроводность & 3,812 & 2 & 624 \\
\hline 14 & технологичность производства & 4,917 & 4 & 19,668 \\
\hline 15 & устойчивочть к агрессивным воздействиям & 4,999 & 5 & 24,995 \\
\hline 16 & пористость & 4,857 & 4 & 19,428 \\
\hline 17 & ремонтопригодность & 4,979 & 3 & 14,937 \\
\hline 18 & устойчивость к атмосферным воздействиям & 3,991 & 2 & 7,982 \\
\hline 19 & устойчивость к образованию трещин & 4,999 & 5 & 24,995 \\
\hline 20 & электропроводность & 3,93 & 2 & 7,86 \\
\hline \multirow[t]{3}{*}{21} & водопоглощение & 4,996 & 5 & 24,98 \\
\hline & сумма & 100,0 & & \\
\hline & \multicolumn{3}{|l|}{ комплексная оценка } & 378,526 \\
\hline
\end{tabular}

условные обозначения :

максимальный показатель потенциала 
Сравнительная характеристика железобетонных и микроармированных бетонных труб

\begin{tabular}{|c|c|c|c|}
\hline № & Наименование фактора & Железобетонные трубопроводы & Бетонные микроармированные трубы \\
\hline 1 & 2 & 3 & 4 \\
\hline 1 & прочность & высокая & $\begin{array}{c}\text { высокая } \\
\text { ввиду подбора оптимального } \\
\text { состава модификаторов }\end{array}$ \\
\hline 2 & $\begin{array}{l}\text { устойчивость } \\
\text { к образованию } \\
\text { трещин }\end{array}$ & $\begin{array}{c}\text { низкая } \\
\text { (возможность появления трещин до приложения экс- } \\
\text { плуатационной нагрузки, на пример, от усадки и } \\
\text { собственных напряжений в железобетоне по техноло- } \\
\text { гическим причинам, от действия внешних нагрузок } \\
\text { из-за низкого сопротивления бетона растяжению; } \\
\text { трещины могут появится вследствие нарушения сцеп- } \\
\text { ления между бетоном и арматурой) }\end{array}$ & $\begin{array}{c}\text { высокая } \\
\text { трещиностойкость }\end{array}$ \\
\hline 3 & $\begin{array}{c}\text { устойчивость } \\
\text { к агрессивным средам }\end{array}$ & низкая & высокая \\
\hline 4 & экономичность & высокая себестоимость & $\begin{array}{c}\text { высокая } \\
\text { ввиду отсутствия необходимости дорогостоящей, } \\
\text { часто дефицитной арматуры; } \\
\text { ввиду повсеместной доступности сырья }\end{array}$ \\
\hline 5 & долговечность & относительно высокая & более высокая (по частоте отказов) \\
\hline 6 & водопоглощение & низкая & $\begin{array}{c}\text { более низкая } \\
\text { ввиду наличия модификаторов } \\
\text { (минеральные, полимерные), которые имеют } \\
\text { площадь поверхности больше чем у цемента }\end{array}$ \\
\hline 7 & коррозийная стойкость & $\begin{array}{c}\text { высокая } \\
\text { подверженность коррозии } \\
\text { (что негативно влияет на долговечность, прочность, } \\
\text { устойчивость и другие показатели) }\end{array}$ & $\begin{array}{c}\text { высокая } \\
\text { стойкость в отношении коррозии }\end{array}$ \\
\hline 8 & объёмная масса (вес) & большой собственный вес & $\begin{array}{c}\text { относительно малый собственный вес } \\
\text { ввиду отсутствия арматуры }\end{array}$ \\
\hline 9 & морозостойкость & высокая & высокая \\
\hline 10 & теплопроводность & $\begin{array}{c}\text { высокая } \\
\text { (наличие собственных напряжений, } \\
\text { вызываемых усадкой бетона } \\
\text { и температурно-влажностными воздействиями) }\end{array}$ & $\begin{array}{c}\text { низкая } \\
\text { теплопроводность }\end{array}$ \\
\hline 11 & пропускная способность & не высокая & $\begin{array}{c}\text { высокая } \\
\text { (сохранение в условиях эксплуатации гладкой } \\
\text { и не корродированной внутренней поверхности) }\end{array}$ \\
\hline 12 & экологичность & высокая & высокая \\
\hline 13 & трудовые затраты & $\begin{array}{c}\text { значительные, } \\
\text { ввиду необходимости привлечения } \\
\text { квалифицированных специалистов } \\
\text { для установки арматуры }\end{array}$ & незначительные \\
\hline 14 & $\begin{array}{c}\text { технологичность производ- } \\
\text { ства }\end{array}$ & $\begin{array}{c}\text { Не высокая, } \\
\text { что усложняется наличием арматуры }\end{array}$ & $\begin{array}{c}\text { высокая, } \\
\text { что достигается за счёт однородной } \\
\text { быстрой уплотняемости бетонной смеси; } \\
\text { автоматизированного производства }\end{array}$ \\
\hline 15 & дополнительные расходы & $\begin{array}{c}\text { наличие дополнительных расходов для специальной } \\
\text { технике и привлечении квалифицированных рабочих, } \\
\text { а также на дефицитный основной материал (железо) }\end{array}$ & простота в монтаже и транспортировке \\
\hline 16 & пористость & низкая & низкая \\
\hline 17 & ремонтопригодность & $\begin{array}{c}\text { низкая, } \\
\text { ввиду наличия арматурного каркаса }\end{array}$ & $\begin{array}{c}\text { высокая, } \\
\text { возможность применения различных вариантов } \\
\text { монтажа; простота в обслуживании, ремонте; } \\
\text { минимальное зарастание }\end{array}$ \\
\hline 18 & $\begin{array}{l}\text { устойчивость к атмосфер- } \\
\text { ным воздействиям }\end{array}$ & высокая & высокая \\
\hline 19 & электропроводность & $\begin{array}{c}\text { высокая, } \\
\text { подверженность разрушающему действию } \\
\text { блуждающих потоков от электротранспорта }\end{array}$ & диалектичность \\
\hline 20 & огнестойкость & высокая & более высокая ввиду низкой теплопроводности \\
\hline 21 & звукопроводность & высокая звукопроводность & более низкая звукопроводность \\
\hline
\end{tabular}




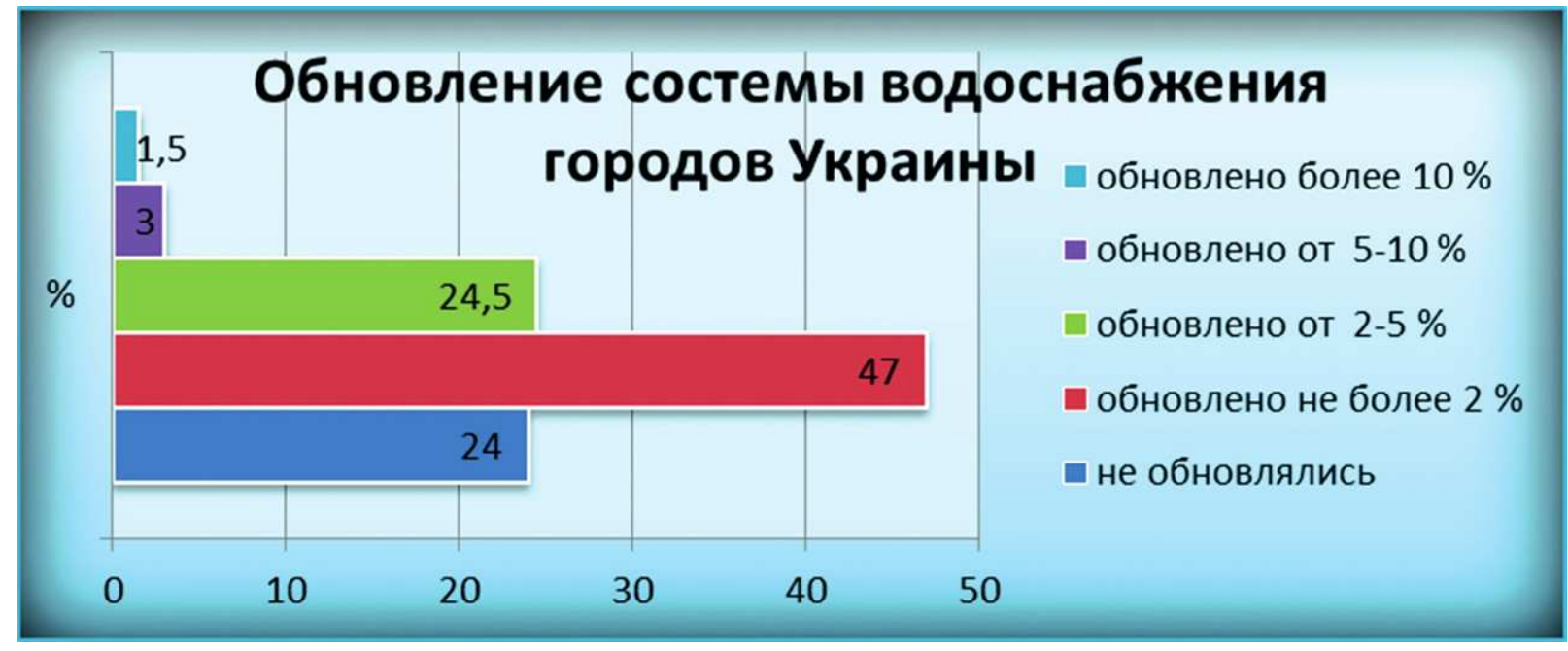

Рис. 1. Обновление системы водоснабжения

соблюдать требования нормативних документов (ДБН, ГОСТов, СНиПов). Данная тенденция затрудняет качественную оценку трубопроводных систем и выбор однозначно эффективного варианта.

В связи с этим был проведен комплексный анализ паказателей и критериев, при изучении специализированной научной литературы, требований соответствующих стрндартов, нормативних документов, в следствии чего были выявлены и сформированы факторы оценки трубопроводов, которые их наиболее полно характеризуют. Для определения значимости выявленных факторов, влияющих на эффективное использование и оценки качества трубопроводов был использован экспертный метод, который включает в себя: анализ существующих трубопроводов, используемых в качестве строительных изделий для водоводов хозяйственно-бытовой, ливневой, промышленной канализации, дренажных, ирригационномелиоративных сетей; согласование результатов проведеного анализа; виявление основных факторов, которые в наибольшей мере влияют на эффективное исспользование и качество трубопроводов, что позволит выявить преимущества и недостатки каждого из видов. Результаты проведенной работы представлены в таблице 1.

В ходе экспертного анализа были исследованы следующие вопросы: какие из факторов являются основными при оценке эффективного использования и качества трубопроводов; степень влияния каждого определённого фактора на качества и эксплуатационные показатели трубопроводов.

Данные полученных исследований позволяют проследить наиболее значимые факторы: прочность, устойчивость к образованию трещин, экономичность, коррозийная стойкость, водопоглащение. Наименьший потенциал имеет фактор звукопроводности ввиду незначительности при эксплуатации в сети водоводов. Полученные приоритеты соответствуют требованиям нормативних документов на соответствующие изделия, и могут применяться для оценки, а так же сравнения различных видов трубопроводных систем из различных материалов. В результате предложенная экспертная оценка позволяет сделать сравнительный анализ эффективности рассматриваемых видов трубопроводов в сети водоснабжения, с учётом рейтинга потенциала каждого из факторов, которая представлена в таблице 2.

\section{Выводы}

В связи с приведенными данными обоснованным обстоятельством является замена малоэффективных железобетонных труб альтернативными микроармированными бетонными трубами.
Проведенный анализ доказывает эффективность замены железобетонных труб разработанными модифицированными трубопроводами, которые обоснованно можно назвать инновационной технологичной моделью системы водоснабжения Украины. Массовое внедрение в производство предложенных трубопроводов является важной задачей, решение которой может обеспечить дальнейшее снижение стоимости строительства и будет дополнительным существенным резервом экономии материала и финансовых затрат.

Литература:

1. Ильин Ю.А. Расчет надежности подачи воды. М.: Стройиздат, 1987. - 320 с.

2. Семененко Н.В, Юнис Б.Н. Определение прочности материала труб по данным предельных разрушающих нагрузок// Збірник наукових проць Української Державної Академії залізничного транспорту №113.-Харків.-2010.-с.103-105.

3. http://www.water.ks.ua/index.php/opredpriyatii/ napravleniyarazvitiya/vodootvedenie/315-2012-0404-11-31-11.html

4. Хорунжий П.Д., Хомутецька Т.П. сучасні інноваційні заходи для поліпшення господарсько-питного водопостачання//Наук. Вісн. Будівництва.-Харьків: ХДТУБА, ХОТВ АБУ, 2011.-Вип.65.-С.315-317.

5. Гончаренко Д.Ф., Алейникова А.И Анализ состояния магистральных водоводов системы водоснабжения г. Харькова. Факторы, влияющие на их эксплуатационную долговечность//Наук. Вісн. Будівництва.-Харьків: ХДТУБА, ХОТВ АБУ, 2013.Вип.72.-С.369-375.

6. Дворкин О.Л. Эффективность химических добавок в бетонах // Бетон и железобетон. - 2003. - № 4. С. 23-25. Абрамов Н.Н. Надежность систем водоснабжения. - М.: Стройиздат, 1979.- 231 с.

7. Гончаренко Д.Ф., Забелин С. А., Бондаренко Д.А., Старкова О.В.Лабораторне Исследования прочностных характеристик стеклопластиковых труб для ремонта и восстановления сетей водоотведения//Наук. Вісн. Будівництва.-Харьків: ХДТУБА, ХОТВ АБУ, 2013.-Вип.70.-С.71-78.

8. Вандоловский А.Г., Юнис Б.Н. Повышение прочности бетона при растяжение путём его модификации // Науковий вісник будівництва №57 Харків, -2010.- c. 206-212.

9. http://www.brainity.ru/business/career/6576/ 